\title{
A Review of Emergency Visits made by Youth and Adults with Autism Spectrum Disorder from the Parent Perspective
}

\author{
Yona Lunsky, Ami Tint, Jonathan A. Weiss, Anna Palucka and Elspeth Bradley
}

This article is (C) Emerald Publishing and permission has been granted for this version to appear here (https://doi.org/10.1108/AIA-08-2017-0019). Emerald does not grant permission for this article to be further copied/distributed or hosted elsewhere without the express permission from Emerald Group Publishing Limited. 


\begin{abstract}
Purpose: Past research has shown individuals with autism spectrum disorder (ASD) visit hospital emergency departments (ED) at high rates. In order to assist individuals with ASD, their families and health care providers to improve ED care, it is important to understand these encounters in greater detail. This study aimed to provide a descriptive summary of the ED experiences of adolescents and adults with ASD, from the perspective of their families.
\end{abstract}

Design/Methodology/Approach: A subset of data from a larger prospective cohort study was used. Specifically, 46 parents of adolescents and adults with ASD provided details concerning 49 ED visits over a 12-month period.

Findings: Results suggest a range of presentations requiring ED use, and also diverse profiles of those with ASD who visited the ED, in terms of age, gender, and ASD severity. While overall degree of satisfaction with care received in the ED was high, parents provided recommendations to improve the ED experiences for their family members with ASD.

Originality/value: This is the first study to provide detailed accounts of ED visits from the perspective of parents of adolescents and adults with ASD. Families play an important role in the lives of individuals with ASD across the lifespan and it is important to include their perspective to improve hospital- based care for those with ASD.

Keywords: Adolescents, Adult, Hospital, Autism spectrum disorder, Emergency department,

This article is (C) Emerald Publishing and permission has been granted for this version to appear here (https://doi.org/10.1108/AIA-08-2017-0019). Emerald does not grant permission for this article to be further copied/distributed or hosted elsewhere without the express permission from Emerald Group Publishing Limited. 
A Review of Emergency Visits made by Youth and Adults with Autism Spectrum

\section{Disorder from the Parent Perspective}

It is well recognized that youth and adults with autism spectrum disorder (ASD) are more likely to visit hospital emergency departments (ED) than their peers without ASD (Deavenport-Saman, Lu, Smith, \& Lin, 2016; Iannuzzi, Chen, Broder-Fingert, \& Bauman, 2015; Liu, Pearl, Kong, \& Murray, 2017; Vohra, Madhavan, \& Sambamoothi, 2016), and that these visits can be stressful for them, their families, and hospital staff (Nicholas et al., 2016; Rooth \& Lindholm Olinder, 2016; Zwaigenbaum et al., 2016). Hospital staff are not well trained to recognize and adapt their practices to meet the needs of those with ASD. The hospitals themselves are unfamiliar stressful settings for those with sensory issues, communication impairments and a need for routine and predictability. Unlike proactive health care interactions, individuals and families visit the ED in crisis, so they are limited in their ability to prepare for these visits appropriately.

In order to assist individuals with ASD, their families and health care providers to improve ED encounters, it is important to understand these encounters in greater detail. Population-based studies can provide some of this information, as can hospital-based charts. However, both of these sources of information rely on the health care provider to record pertinent details, and neither offers the perspective of the family caregiver. Only two studies have provided descriptions of ED visits by individuals with ASD using chart information (Cohen-Silver, Muskat \& Ratnapalan, 2014; Tint, Robinson, \& Lunsky, 2011). In a chart audit review of 39 ED visits involving 24 individuals with ASD and

This article is (C) Emerald Publishing and permission has been granted for this version to appear here (https://doi.org/10.1108/AIA-08-2017-0019). Emerald does not grant permission for this article to be further copied/distributed or hosted elsewhere without the express permission from Emerald Group Publishing Limited. 
intellectual disability (ID) ranging in age from 16 to 72 years, the majority of ED visits were a result of physical or verbal aggression (Tint et al., 2011). Restraints were used during $53 \%$ of psychiatric ED visits; no restraint use was documented during medically related visits. This study, however, was limited to individuals connected to community agencies serving individuals with ID. More recently, Cohen-Silver et al. (2014) conducted a chart review of $160 \mathrm{ED}$ visits by 130 children with ASD. The most common presentations were 'other' medical concerns (fever, headache, cough/congestion) and infection, with the average length of stay in the ED over six hours. This study was limited to children, and focused only on one hospital. A recent paper explored predictors of ED visits for a cohort of families with adolescents and adults with ASD from Ontario (Lunsky et al. 2017), where nearly one in four individuals used the ED over the course of a year, according to caregiver report. Those that did and did not use the ED did not differ with regard to gender, age, or autism severity. Previous ED visits, family distress and prior life events predicted future visits. While these studies offer information on why some individuals visit their hospital ED when others did not, they do not provide details on what occurred in those visits. Further, no studies have provided detailed information on ED encounters from the parent perspective, despite their heavily relied upon role in the care of their adolescent and adult-age children (Mazefsky \& White, 2014). In the current paper, a summary of families' experiences in the ED is provided, when they involve an adolescent or adult patient with ASD.

\section{Methods}

\section{Participants}

This article is (C) Emerald Publishing and permission has been granted for this version to appear here (https://doi.org/10.1108/AIA-08-2017-0019). Emerald does not grant permission for this article to be further copied/distributed or hosted elsewhere without the express permission from Emerald Group Publishing Limited. 
This study describes ED visits made by 46 individuals whose parents provided ED visit descriptions, from a larger prospective cohort study on ED use in adolescents and adults with $\operatorname{ASD}(N=284$; reference removed for peer review). The criteria for inclusion in the larger study were as follows: (a) individuals with ASD were over the age of 11 (b) had received a formal diagnosis of ASD by qualified health professional and (c) met a cutoff score of 12 or more on the Social Communication Questionnaire (SCQ; Rutter, Bailey \& Lord 2003). Family caregivers provided baseline information and then completed six bimonthly surveys concerning service use in reference to the preceding two months. All 284 parents in the cohort completed their baseline and final follow up survey between a 12 to 18 -month period. On average, the 284 participants completed at total of 4.33 surveys $(S D=1.41)$ over 14.53 months $(S D=1.50)$. All participants were recruited from postings on provincial ASD support and advocacy organizations' websites. Informed consent was provided prior to completing the initial survey. Participants were able to complete surveys via mail, telephone interview or online. Most participants (78.5\%) completed their surveys online.

For the current analyses, we focused on the subgroup of participants who provided descriptive information about their child's ED visit during the study period $(n=$ 46), representing $73 \%$ of the individuals who reportedly used the ED in the larger study. These individuals did not differ from those who reported ED use but did not provide detail in the larger study with respect to parent (age, marital status, education, ethnicity, median neighborhood income) or individual with ASD demographics (age, sex, ID status, presence of medical or psychiatric diagnosis). The survey respondents in this subsample (93.5\% female) were 32 to 65 years of age $(M=49.93, S D=6.75)$ and the majority This article is (C) Emerald Publishing and permission has been granted for this version to appear here (https://doi.org/10.1108/AIA-08-2017-0019). Emerald does not grant permission for this article to be further copied/distributed or hosted elsewhere without the express permission from Emerald Group Publishing Limited. 
(69.6\%) reported being married or living with a partner at baseline. The forward sortation index (first three digits) of participants' postal codes was used to find the median neighbourhood income from the Canadian Census (Statistics Canada 2006). Median neighbourhood incomes ranged from CAN $\$ 40,895$ to CAN $\$ 99,165$. Most participants identified as Caucasian $(87.0 \%)$ and had completed a college or university degree $(76.1 \%)$.

\section{Measures}

Demographics. Demographics included age, sex, intellectual disability (ID) status, psychiatric and/or medical comorbidities, and history of ED use. ID status was dichotomized into those who had an ID (i.e., mild to profound ID) and those who did not (i.e., gifted, normal and borderline intelligence). Parents were asked to provide current medical and psychiatric diagnoses for their child with ASD; responses for each were dichotomized. Parents also indicated (yes/no) whether their family member visited the ED during the 12 months prior to baseline survey completion.

ED visits. Parents were asked to provide descriptions of their family member's ED use during the previous two months in each survey. To ensure the standardisation of sampling period across participants, only ED visits during the 12 months that preceded participants' final survey were included. Parent descriptions of ED visits were coded as psychiatric or medical in nature by two researchers with $98 \%$ inter-rater agreement. Any disagreements were resolved through discussion with the senior author. If parents provided descriptions for more than one ED visit, each visit was coded separately. For the purposes of the current analyses, we included only the first medical and first psychiatric ED visit described by each parent; three individuals were classified as having both a This article is (C) Emerald Publishing and permission has been granted for this version to appear here (https://doi.org/10.1108/AIA-08-2017-0019). Emerald does not grant permission for this article to be further copied/distributed or hosted elsewhere without the express permission from Emerald Group Publishing Limited. 
medical emergency and a psychiatric ED visit. Parents were asked to provide information about their family member's ED experiences, including presenting concerns, mode of arrival, and day and time of arrival and departure. Arrival times were coded according to four six-hour periods. Parents were also asked to indicate yes/no if their family member experienced the following in the ED: taken to separate quiet room/area and/or restraints (physical and/or chemical) used. Additionally, parents were asked to rate their satisfaction with the treatment received in the ED based on a five-point Likert scale with higher scores indicative of greater satisfaction ("How satisfied were you with the treatment received in the ED?"). All parents were asked if they had any recommendations on how to improve ED experiences through an open text response option. Two authors reviewed and coded these responses.

This study received Research Ethics Board approval from the Centre for Addiction and Mental Health. Consenting parents understood that the information they provided, including open text responses would be included in analysis.

\section{Results}

Individuals with ASD (73.9\% male) were 12 to 39 years of age $(M=18.02$ years, $S D=5.34$ ). Approximately $46 \%$ of the sample was reported to have ID. Over half (58.7\%) had a co-occurring psychiatric diagnosis while $34.8 \%$ had a comorbid medical condition. Table 1 displays demographic profiles of the 46 individuals with ASD who visited the ED according to type of visit. Of the total $49 \mathrm{ED}$ visits, 31 were due to medical concerns and the remaining 18 visits were due to psychiatric concerns. Age, sex, ID status, co-occurring medical and psychiatric conditions, and history of ED visits varied for both medical and psychiatric related visits. Of note, each of the three This article is (C) Emerald Publishing and permission has been granted for this version to appear here (https://doi.org/10.1108/AIA-08-2017-0019). Emerald does not grant permission for this article to be further copied/distributed or hosted elsewhere without the express permission from Emerald Group Publishing Limited. 
individuals who presented to the ED for medical as well as psychiatric concerns on separate occasions had additionally visited the ED during the year prior to baseline completion.

\section{Insert Table 1}

Table 2 presents a summary of presenting concerns leading to ED visits. Injuries accounted for the highest number of medical related visits while risk to self was the most common psychiatric related reason. Family members brought individuals to the ED in the majority of incidents $(n=29,59.2 \%)$. Other modes of arrival included police and/or ambulance escort ( $n=14,28.6 \%$ ) or other individuals (e.g., friend, caregiver; $n=3$, 6.1\%). In two incidents the individual with ASD went to the ED by their own accord and information regarding the mode of arrival was unknown for one incident. For the 37 visits for which date of arrival was provided, the distribution of ED visits across the seven days of the week (see Table 3). Time of arrival was provided for 44 incidents and is shown in Table 4 according to morning ( 6 am to $12 \mathrm{pm}$ ), afternoon (12 pm to $6 \mathrm{pm}$ ), evening (6 pm to $12 \mathrm{am}$ ), and overnight (12 am to 6 am) visits. Total time in the ED ranged from one hour to 29 hours $(M=5.49 ; M d n=4.5 ; S D=4.86)$.

Insert Table 2

This article is (C) Emerald Publishing and permission has been granted for this version to appear here (https://doi.org/10.1108/AIA-08-2017-0019). Emerald does not grant permission for this article to be further copied/distributed or hosted elsewhere without the express permission from Emerald Group Publishing Limited. 
Insert Table 3

Insert Table 4

Individuals were taken to a separate quiet place in $51 \%(n=25)$ of visits.

Restraints were used in 15 (30.6\%) of ED visits (eight psychiatric visits and seven medically related visits). Physical restraints (i.e., security staff and/or mechanical restraints) were used during nine (18.4\%) incidents and chemical sedation was used during 12 (24.5\%) incidents; both mechanical and chemical restraints were used during six $(12.2 \%)$ ED visits.

Parents provided satisfaction ratings with treatment received in the ED for 48 (97.9\%) visits. Parent satisfaction ratings ranged from one (very dissatisfied) to five (very satisfied; $M=3.63, S D=1.38)$, with the majority of parents $(n=32,65.3 \%)$ being satisfied to very satisfied (see Table 5).

\section{Insert Table 5}

In total, 15 parents provided open text responses concerning recommendations for care improvements in the ED. Responses were coded into six categories: 1) changes in the ED process; 2) specific accommodations for individuals with ASD; 3) greater empathy needed; 4) required services in hospital and community; 5) greater knowledge of This article is (C) Emerald Publishing and permission has been granted for this version to appear here (https://doi.org/10.1108/AIA-08-2017-0019). Emerald does not grant permission for this article to be further copied/distributed or hosted elsewhere without the express permission from Emerald Group Publishing Limited. 
ASD needed; 6) listening to family expertise. The most common types of recommendation focused on changes in the ED process itself and suggestions concerning adjustments or accommodations specific to individuals with ASD that could be made in hospital (e.g., shortened wait times, individuals with ASD to be seen by psychiatrists as compared to ED physicians). Four parents specifically recommended that staff learn to be more empathic and an equal number of parents spoke about needed services in the hospital and community that were absent (e.g., addictions based mental health services for individuals with ASD). Finally, two parents gave comments about the need to listen to and respect family expertise about their son or daughter.

\section{Discussion}

The current study set out to describe ED visits made by adolescents and adults with ASD over the course of one year, according to their parents. Findings suggest a range of presentations requiring ED use, and also diverse profiles of those with ASD who visited the ED, in terms of age, gender, and ASD severity. Any efforts to improve ED experiences should take into account that there is no single demographic or clinical profile associated with ED visits. Although two thirds of parents rated their visits as satisfactory or very satisfactory, , there remain many ways in which ED's could improve the care they provide to the autism community.

Adolescents and adults with ASD visit the hospital ED for both psychiatric and medical reasons. Risk to self was the most common presenting concern with this group, in terms of psychiatric emergencies. Speaking to the frustration one mother felt about the inadequate care her son received in the ED when he presented with suicidal ideation:

"This is the third time my son has been to the emergency with suicidal ideations. Each This article is (C) Emerald Publishing and permission has been granted for this version to appear here (https://doi.org/10.1108/AIA-08-2017-0019). Emerald does not grant permission for this article to be further copied/distributed or hosted elsewhere without the express permission from Emerald Group Publishing Limited. 
time he is sent home. Does he have to attempt suicide before anyone takes notice?" Greater attention needs to be paid to recognizing risk of self-harm and determining appropriate community and hospital based resources (Cassidy et al. 2014; Cassidy \& Rodgers 2017; Lai et al. 2017). Injuries were the most common medical presentation, and individuals with ASD may be at an increased risk of accidents and injuries compared to the general population (Kalb et al. 2016; Schlenz et al. 2015). Further research is needed to develop appropriate injury prevention and monitoring in the community.

Although not used in all circumstances, parents reported restraint use in over one third of ED encounters, including in both medical and psychiatric emergencies. There clearly may be some situations where restraints are required, when the safety of the person or others is placed at serious imminent risk (Centers for Medicare and Medicaid Services, 2012); however, considerable research into positive behavioral supports outside of the ED confirms that there are many evidence-based strategies for reducing the need for restraint (Bambara et al., 2001; Lavigna \& Willis, 2012; LeBel et al., 2004; Singh et al., 2009). Health care providers can work together with individuals and with families to minimize restraint and to allow choice with regard to method applied, if it is needed, in order to minimize distress (Fish \& Hatton, 2017). Discussion surrounding restraint use can occur prior to emergencies and it may be helpful in these situations to have written documentation about need for restraint and restraint preferences/guidance as part of a care plan, prepared prior to the emergency, and on file at the hospital for all hospital staff. In the current study, one mother described the difficulties her son experienced in the ED despite her specific care requests:

This article is (C) Emerald Publishing and permission has been granted for this version to appear here (https://doi.org/10.1108/AIA-08-2017-0019). Emerald does not grant permission for this article to be further copied/distributed or hosted elsewhere without the express permission from Emerald Group Publishing Limited. 
I told the doctor that in order to get stitches done [son] would need to be 'put out'. He has Autism, anxiety and OCD issues. He is also 18 years of age and very fit/strong. I preferred that he be 'put out' because in the past, we have tried to give him sedatives for various procedures (i.e. dental work, MRI, etc.) and he is able to overcome the sedative due to his high anxiety. This is documented in the hospital chart from previous procedures/tests. We, as parents, are aware of the risks with getting 'put out' ...but we did not want him to be traumatized for any future emerg visits. The doctor chose to only give him a sedative, and after 1.5 to 2 hours of waiting for the sedative to work, which it did not, got security to apply restraints to his feet and one arm. This did not go well, and then an I.V. was put in for further medication/sedatives. This was EXTREMELY hard on [son], as well as us (his parents), and staff.

How chemical and mechanical restraint feels to someone with ASD may be different to how it is experienced by someone else. Sensory sensitivities, common in ASD, are unique to each individual; one person may find mechanical restraint soothing and containing, whereas another person may experience the wrong kind of touch, even if it is "gentle" to an outsider, as very threatening and become extremely agitated. In a similar way, one person may be extremely sensitive to a low dose of chemical restraint and another may not appear to respond to even a high dose. Further, the experience of a loss of control and confusion may occur if a person does not understand why restraints are being applied or if it is against their wishes (Fish \& Hatton, 2017; Ling et al., 2015). Specific accommodations may need to be made in the ED based on a person's unique profile (McGonigle et al. 2014). Given how common restraint can be in the ED for This article is (C) Emerald Publishing and permission has been granted for this version to appear here (https://doi.org/10.1108/AIA-08-2017-0019). Emerald does not grant permission for this article to be further copied/distributed or hosted elsewhere without the express permission from Emerald Group Publishing Limited. 
individuals with ASD (Lunsky et al. 2014), some social stories to help individuals understand and prepare for restraint might also be helpful. Further research into restraint use in hospitals is warranted.

Fifteen of the 49 parents who provided ED descriptions in the current study also offered specific suggestions to improve emergency care. It is important for health care providers and administrators to learn from the experience of families to improve hospital based care. Continued investment is needed in educating ED staff about ASD and the diversity of presentations, with an emphasis on the types of accommodations that can be made, such as involving psychiatry, using quiet rooms, preparing for restraint use, reducing wait times, taking additional time to listen to patient and respond to their questions. Hospital passports and other communication tools can assist with this (Heifetz \& Lunsky, 2018; Venkat, Migyanka, Cramer, \& McGonigle, 2016). In addition to service-based accommodations, it is necessary to find ways to help health care providers develop greater empathy for those with ASD and families. Initiatives that help providers understand and accept ASD led by those with autism and families can be effective in this regard. Some families expressed concerns about service gaps, making ED recommendations not helpful. Hospitals need to coordinate efforts with community to make sure that the capacity is there to respond to and over time prevent all types of emergencies.

In interpreting study findings it is important to keep in mind several limitations. All results are based on parent report, without documentation from the hospitals themselves, and without soliciting the perspective of clinicians or individuals with ASD. There is also a subgroup of individuals who have had repeat visits to hospital, but the This article is (C) Emerald Publishing and permission has been granted for this version to appear here (https://doi.org/10.1108/AIA-08-2017-0019). Emerald does not grant permission for this article to be further copied/distributed or hosted elsewhere without the express permission from Emerald Group Publishing Limited. 
current study only summarized the first visit description. It would be important to understand the experience of repeat visits in greater detail. Current results are based on a convenience sample of parents who were willing to prospectively report on ED experiences over time. This group was highly educated, mostly Caucasian, and affluent, and does not represent all families. Furthermore, it is possible that parents for whom ED visits were very stressful might not have the time, stamina or ability to report on them in a timely fashion. Efforts such as this need to be complemented by administrative studies based on hospital information, as well as qualitative interviews from the perspective of those with ASD who have visited hospital.

Funding: This research was funded by the Canadian Institutes of Health Research (MOP 102677). Jonathan A. Weiss was supported by the Chair in ASD Treatment and Care Research (Canadian Institutes of Health Research RN162466-284208 in partnership with NeuroDevNet, Sinneave Family Foundation, CASDA, Autism Speaks Canada and Health Canada)

This article is (C) Emerald Publishing and permission has been granted for this version to appear here (https://doi.org/10.1108/AIA-08-2017-0019). Emerald does not grant permission for this article to be further copied/distributed or hosted elsewhere without the express permission from Emerald Group Publishing Limited. 


\section{References}

Bambara, L.M., Gomez, O., Koger, F., Lohrmann-O'Rourke, S. and Xin, Y.P., 2001. More than techniques: Team members' perspectives on implementing positive supports for adults with severe challenging behaviors. Journal of the Association for Persons with Severe Handicaps, 26(4), pp.213-228.

Cassidy, S., Bradley, P., Robinson, J., Allison, C., McHugh, M. and Baron-Cohen, S., 2014. Suicidal ideation and suicide plans or attempts in adults with Asperger's syndrome attending a specialist diagnostic clinic: a clinical cohort study. The Lancet Psychiatry, 1(2), pp.142-147.

Cassidy, S., \& Rodgers, J. (2017). Understanding and prevention of suicide in autism. The Lancet Psychiatry.

Centers for Medicare and Medicaid Services, HHS. (2012). Condition of participation: Patients' rights (CFR Title 42 Section 482.13). Washington, DC: U.S. Government Printing Office.

Cohen-Silver, J.H., Muskat, B. and Ratnapalan, S., 2014. Autism in the emergency department. Clinical Pediatrics, 53(12), pp.1134-1138.

Deavenport-Saman, A., Lu, Y., Smith, K. and Yin, L., 2016. Do children with autism overutilize the emergency department? Examining visit urgency and subsequent hospital admissions. Maternal and Child Health Journal, 20(2), pp.306-314.

Fish, R. and Hatton, C., 2017. Gendered experiences of physical restraint on locked wards for women. Disability \& Society, 32(6),pp.790-809.

Heifetz, M., \& Lunsky, Y. (2018). Implementation and evaluation of health passport

This article is (C) Emerald Publishing and permission has been granted for this version to appear here (https://doi.org/10.1108/AIA-08-2017-0019). Emerald does not grant permission for this article to be further copied/distributed or hosted elsewhere without the express permission from Emerald Group Publishing Limited. 
communication tools in emergency departments. Research in Developmental Disabilities, 72, 23-32.

Iannuzzi, D.A., Cheng, E.R., Broder-Fingert, S. and Bauman, M.L., 2015. Brief report: Emergency department utilization by individuals with autism. Journal of Autism and Developmental Disorders, 45(4), pp.1096-1102.

Kalb, L. G., Vasa, R. A., Ballard, E. D., Woods, S., Goldstein, M., \& Wilcox, H. C. (2016). Epidemiology of injury-related emergency department visits in the US among youth with autism spectrum disorder. Journal of Autism and Developmental Disorders, 46(8), 2756-2763.

Lai, J.K., Rhee, E. and Nicholas, D., 2017. Suicidality in Autism Spectrum Disorder: a Commentary. Advances in Neurodevelopmental Disorders, pp.1-6.

LaVigna, G.W. and Willis, T.J., 2012. The efficacy of positive behavioural support with the most challenging behaviour: The evidence and its implications. Journal of Intellectual and Developmental Disability, 37(3), pp.185-195.

LeBel, J., Stromberg, N., Duckworth, K., Kerzner, J., Goldstein, R., Weeks, M., Harper, G. and Sudders, M., 2004. Child and adolescent inpatient restraint reduction: A state initiative to promote strength-based care. Journal of the American Academy of Child \& Adolescent Psychiatry, 43(1), pp.37-45.

Ling, S., Cleverley, K. and Perivolaris, A., 2015. Understanding mental health service user experiences of restraint through debriefing: A qualitative analysis. The Canadian Journal of Psychiatry, 60(9), pp.386-392.

Liu, G., Pearl, A.M., Kong, L., Leslie, D.L. and Murray, M.J., 2017. A profile on

This article is (C) Emerald Publishing and permission has been granted for this version to appear here (https://doi.org/10.1108/AIA-08-2017-0019). Emerald does not grant permission for this article to be further copied/distributed or hosted elsewhere without the express permission from Emerald Group Publishing Limited. 
emergency department utilization in adolescents and young adults with Autism Spectrum Disorders. Journal of Autism and Developmental Disorders, 47(2), pp.347-358.

Lunsky, Y., Paquette-Smith, M., Weiss, J.A. and Lee, J., 2014. Predictors of emergency service use in adolescents and adults with autism spectrum disorder living with family. Emergency Medicine Journal, 32(10), pp. 787-792.

Lunsky, Y., Weiss, J.A., Paquette-Smith, M., Durbin, A., Tint, A., Palucka, A.M. and Bradley, E., 2017. Predictors of emergency department use by adolescents and adults with autism spectrum disorder: a prospective cohort study. $B M J$ Open, 7(7), p.e017377.

Mazefsky, C.A. and White, S.W., 2014. Adults with autism. Handbook of Autism and Pervasive Developmental Disorders, Fourth Edition.

McGonigle, J.J., Venkat, A., Beresford, C., Campbell, T.P. and Gabriels, R.L., 2014. Management of Agitation in Individuals with Autism Spectrum Disorders in the Emergency Department. Child and Adolescent Psychiatric Clinics, 23(1), pp.8395.

Nicholas, D.B., Zwaigenbaum, L., Muskat, B., Craig, W.R., Newton, A.S., Kilmer, C., Greenblatt, A., Roberts, W. and Cohen-Silver, J., 2016. Experiences of emergency department care from the perspective of families in which a child has autism spectrum disorder. Social Work in Health Care, 55(6), pp.409-426.

Rooth, E. and Olinder, A.L., 2016. Nurses' experiences of giving care to children with autism spectrum disorder within somatic emergency care. Scientific Times Journal of Paediatrics, 1(1), pp.1-11

This article is (C) Emerald Publishing and permission has been granted for this version to appear here (https://doi.org/10.1108/AIA-08-2017-0019). Emerald does not grant permission for this article to be further copied/distributed or hosted elsewhere without the express permission from Emerald Group Publishing Limited. 
Rutter, M., Bailey, A. and Lord, C., 2003. SCQ. The Social Communication

Questionnaire. Torrance, CA: Western Psychological Services.

Schlenz, A. M., Carpenter, L. A., Bradley, C., Charles, J., \& Boan, A. (2015). Age differences in emergency department visits and inpatient hospitalizations in preadolescent and adolescent youth with Autism Spectrum Disorders. Journal of Autism and Developmental Disorders, 45(8), 2382-2391.

Singh, N.N., Lancioni, G.E., Winton, A.S., Singh, A.N., Adkins, A.D. and Singh, J., 2009. Mindful staff can reduce the use of physical restraints when providing care to individuals with intellectual disabilities. Journal of Applied Research in Intellectual Disabilities, 22(2), pp.194-202.

Statistics Canada (2006). Census Forward Sortation Area. Ottawa, ON, Canada: Geography Division.

Tint, A., Robinson, S., \& Lunsky, Y. 2011. Emergency department assessment and outcome in individuals with Autism Spectrum Disorders. Journal on Developmental Disabilities, 17(2), pp. 56-59.

Venkat, A., Migyanka, J.M., Cramer, R., \& McGonigle, J.J. (2016). An instrument to prepare for acute care of the individual with Autism Spectrum Disorder in the emergency department. Journal of Autism and Developmental Disorders, 46(7), 2565-2569.

Vohra, R., Madhavan, S. and Sambamoorthi, U., 2016. Emergency department use among adults with autism spectrum disorders (ASD). Journal of Autism and Developmental Disorders, 46(4), pp.1441-1454.

Zwaigenbaum, L., Nicholas, D.B., Muskat, B., Kilmer, C., Newton, A.S., Craig, W.R., This article is $(\mathcal{C}$ Emerald Publishing and permission has been granted for this version to appear here (https://doi.org/10.1108/AIA-08-2017-0019). Emerald does not grant permission for this article to be further copied/distributed or hosted elsewhere without the express permission from Emerald Group Publishing Limited. 
Ratnapalan, S., Cohen-Silver, J., Greenblatt, A., Roberts, W. and Sharon, R., 2016. Perspectives of health care providers regarding emergency department care of children and youth with autism spectrum disorder. Journal of Autism and Developmental Disorders, 46(5), pp.1725-1736.

This article is (C) Emerald Publishing and permission has been granted for this version to appear here (https://doi.org/10.1108/AIA-08-2017-0019). Emerald does not grant permission for this article to be further copied/distributed or hosted elsewhere without the express permission from Emerald Group Publishing Limited. 
Table 1. Sample demographics by type of ED visit $(N=46)$

\begin{tabular}{|c|c|c|c|c|c|c|}
\hline & Age & Sex & ID status & $\begin{array}{l}\text { Psychiatric } \\
\text { Diagnosis }\end{array}$ & $\begin{array}{l}\text { Medical } \\
\text { Diagnosis }\end{array}$ & $\begin{array}{l}\text { ED visit in } \\
\text { year prior }\end{array}$ \\
\hline \multicolumn{7}{|l|}{ Medical ED visits } \\
\hline & 12 & Male & ID & No & No & No \\
\hline & 12 & Male & ID & No & Yes & Yes \\
\hline & 13 & Male & ID & No & No & No \\
\hline & 13 & Male & Unknown & Yes & No & No \\
\hline & 13 & Male & No ID & Yes & No & No \\
\hline & 13 & Male & No ID & Yes & Yes & Yes \\
\hline & 13 & Male & ID & No & No & No \\
\hline & 13 & Male & ID & Yes & Yes & Yes \\
\hline & 15 & Male & No ID & No & Yes & No \\
\hline & 16 & Male & No ID & No & No & No \\
\hline & 16 & Make & No ID & Yes & Yes & Yes \\
\hline & 17 & Male & ID & No & No & No \\
\hline & 17 & Female & No ID & Yes & No & No \\
\hline & 17 & Male & No ID & Yes & No & No \\
\hline & 17 & Male & No ID & Yes & No & No \\
\hline & 17 & Male & ID & No & Yes & Yes \\
\hline & 18 & Male & ID & Yes & No & Yes \\
\hline & 19 & Male & No ID & Yes & No & No \\
\hline & 19 & Male & ID & No & Yes & Yes \\
\hline & 19 & Female & ID & Yes & Yes & No \\
\hline & 19 & Male & No ID & Yes & Yes & No \\
\hline & 20 & Male & No ID & Yes & No & Yes \\
\hline & 20 & Female & No ID & Yes & No & Yes \\
\hline & 21 & Male & ID & No & Yes & Yes \\
\hline & 23 & Female & No ID & Yes & No & No \\
\hline & 26 & Female & Unknown & Yes & No & Yes \\
\hline & 28 & Female & ID & No & Yes & Yes \\
\hline & 28 & Male & ID & No & Yes & No \\
\hline \multicolumn{7}{|l|}{ Psychiatric ED visits } \\
\hline & 12 & Female & No ID & Yes & No & No \\
\hline & 13 & Female & ID & No & Yes & Yes \\
\hline & 13 & Female & ID & Yes & No & No \\
\hline & 14 & Male & Unknown & Yes & No & Yes \\
\hline & 14 & Male & No ID & Yes & No & No \\
\hline & 15 & Female & No ID & No & No & No \\
\hline & 16 & Male & No ID & No & No & No \\
\hline & 16 & Male & No ID & No & No & Yes \\
\hline & 19 & Male & ID & Yes & Yes & No \\
\hline & 19 & Male & ID & No & No & No \\
\hline & 20 & Male & ID & Yes & No & No \\
\hline
\end{tabular}

This article is (C) Emerald Publishing and permission has been granted for this version to appear here (https://doi.org/10.1108/AIA-08-2017-0019). Emerald does not grant permission for this article to be further copied/distributed or hosted elsewhere without the express permission from Emerald Group Publishing Limited. 


\begin{tabular}{llllll}
\hline 22 & Male & ID & Yes & No & Yes \\
23 & Male & ID & No & Yes & No \\
26 & Male & No ID & Yes & Yes & No \\
39 & Female & No ID & Yes & No & No
\end{tabular}

Medical and

Psychiatric ED visits

\begin{tabular}{llllll}
13 & Female & ID & No & No & Yes \\
19 & Male & No ID & Yes & No & Yes \\
22 & Male & No ID & Yes & No & Yes \\
\hline
\end{tabular}

This article is (C) Emerald Publishing and permission has been granted for this version to appear here (https://doi.org/10.1108/AIA-08-2017-0019). Emerald does not grant permission for this article to be further copied/distributed or hosted elsewhere without the express permission from Emerald Group Publishing Limited. 
Table 2. Presenting Concerns $(N=49)$

\begin{tabular}{|c|c|c|}
\hline Presenting Concerns & $\mathrm{N}$ & Example \\
\hline \multicolumn{3}{|l|}{ Medical } \\
\hline Injury & 10 & Individual slipped on ice and injured knee \\
\hline Gastrointestinal & 4 & Individual had abdominal pain due to gallstones \\
\hline Infection & 4 & Individual required antibiotics for sinusitis \\
\hline $\begin{array}{l}\text { Unknown medical } \\
\text { concern }\end{array}$ & 4 & $\mathrm{n} / \mathrm{a}$ \\
\hline $\begin{array}{l}\text { Sedation required for } \\
\text { medical procedure }\end{array}$ & 3 & Individual required sedation for blood tests \\
\hline Genitourinary & 2 & $\begin{array}{l}\text { Individual required treatment for sexually } \\
\text { transmitted disease }\end{array}$ \\
\hline Allergic reaction & 2 & Individual experienced anaphylaxis symptoms \\
\hline $\begin{array}{l}\text { Respiratory and/or } \\
\text { cardiovascular }\end{array}$ & 2 & Individual experienced breathing difficulties \\
\hline \multicolumn{3}{|l|}{ Psychiatric } \\
\hline $\begin{array}{l}\text { Self harm and/or } \\
\text { suicidality }\end{array}$ & 5 & $\begin{array}{l}\text { Individual attempted suicide by lying on train } \\
\text { tracks }\end{array}$ \\
\hline $\begin{array}{l}\text { Physical assault towards } \\
\text { family member }\end{array}$ & 3 & Individual pushed sibling down a flight of stairs \\
\hline Danger to self and others & 3 & $\begin{array}{l}\text { Individual was harming self and physically } \\
\text { aggressive towards others }\end{array}$ \\
\hline Other psychiatric issue & 3 & Individual experienced symptoms of psychosis \\
\hline Elopement & 2 & Individual left group home without permission \\
\hline $\begin{array}{l}\text { Unknown psychiatric } \\
\text { issue }\end{array}$ & 2 & $\mathrm{n} / \mathrm{a}$ \\
\hline
\end{tabular}

This article is (C) Emerald Publishing and permission has been granted for this version to appear here (https://doi.org/10.1108/AIA-08-2017-0019). Emerald does not grant permission for this article to be further copied/distributed or hosted elsewhere without the express permission from Emerald Group Publishing Limited. 
Table 3. ED Visits by Day of Week $(n=37)$

\begin{tabular}{ll}
\hline Day & $n(\%)$ \\
\hline Sunday & $5(10.2)$ \\
Monday & $5(10.2)$ \\
Tuesday & $3(6.1)$ \\
Wednesday & $8(16.3)$ \\
Thursday & $6(12.2)$ \\
Friday & $6(12.2)$ \\
Saturday & $4(8.2)$ \\
\hline
\end{tabular}

This article is (C) Emerald Publishing and permission has been granted for this version to appear here (https://doi.org/10.1108/AIA-08-2017-0019). Emerald does not grant permission for this article to be further copied/distributed or hosted elsewhere without the express permission from Emerald Group Publishing Limited. 
Table 4. ED Visits by Time of Day $(n=44)$

\begin{tabular}{|l|l|}
\hline Time of Day & $n(\%)$ \\
\hline Morning & $16(32.7)$ \\
\hline Afternoon & $14(28.6)$ \\
\hline Evening & $12(24.5)$ \\
\hline Overnight & $2(4.1)$ \\
\hline
\end{tabular}

This article is (C) Emerald Publishing and permission has been granted for this version to appear here (https://doi.org/10.1108/AIA-08-2017-0019). Emerald does not grant permission for this article to be further copied/distributed or hosted elsewhere without the express permission from Emerald Group Publishing Limited. 
Table 5. ED Visits by Parent Satisfaction Rating $(n=48)$

\begin{tabular}{|l|l|}
\hline Rating & $n(\%)$ \\
\hline Very Dissatisfied & $7(14.3)$ \\
\hline Dissatisfied & $3(6.1)$ \\
\hline Neutral & $6(12.2)$ \\
\hline Satisfied & $17(34.7)$ \\
\hline Very Satisfied & $15(30.6)$ \\
\hline
\end{tabular}

This article is (C) Emerald Publishing and permission has been granted for this version to appear here (https://doi.org/10.1108/AIA-08-2017-0019). Emerald does not grant permission for this article to be further copied/distributed or hosted elsewhere without the express permission from Emerald Group Publishing Limited. 